do consentimento informado, iniciou-se o tratamento endodôntico do dente. Foi realizada a instrumentação mecânica com limas ProTaper Gold ${ }^{\circledR}$ até F4 e a obturação foi executada com guta-percha e cimento AH Plus ${ }^{\circledR}$. A restauração definitiva foi efetuada em resina composta. Após o tratamento e no follow-up de cinco meses o dente apresentou resultados estéticos e funcionais satisfatórios.

Discussão e conclusões: Segundo a International Association of Dental Traumatology o tratamento de fraturas que envolvam esmalte, dentina e polpa varia consoante a maturidade do desenvolvimento apical do dente definitivo lesado. No presente caso o tratamento endodôntico foi realizado e num follow-up de 5 meses, o dente apresentou resultados bastante satisfatórios. Concluímos assim que um diagnóstico, planeamento e acompanhamento do tratamento adequados, são importantes para garantir resultados favoráveis.

http://doi.org/10.24873/j.rpemd.2018.11.302

\section{\#066 A Importância Da Disjunção No Tratamento Do Desvio Mandibular - Caso Clínico}

Inês Portas*, Ana Raquel Garcia Barata, Sara Rua, Valter Alves, Gunel Kizi, Ana Delgado

Instituto Universitário Egas Moniz

Introdução: A mordida cruzada posterior é uma má-oclusão frequente com prevalência de cerca de 8-22\%, que pode ser unilateral ou bilateral, em alguns dentes ou total. A apresentação mais comum é uma mordida unilateral com desvio da mandíbula em direção ao lado da mordida cruzada, que ocorre em 80-97\% dos casos. Este tipo de má-oclusão é causado geralmente por interferências dentárias. O desvio pode vir a produzir uma disfunção da articulação temporomandibular, dor muscular e até alteração no crescimento facial provocando assimetria facial. Desta forma, o tratamento precoce é essencial no restabelecimento do equilíbrio muscular. A disjunção maxilar é considerada o tratamento de eleição desta má-oclusão, pois promove a correção da diminuição transversal da maxila e o desvio mandibular. Os disjuntores que incorporam pistas oclusais de acrílico, ao promoverem a desoclusão dentária, são mais indicados em pacientes com mordida cruzada com interferências oclusais. O objetivo deste trabalho é apresentar um caso clínico de mordida cruzada posterior unilateral com desvio mandibular em que a abordagem clínica consistiu na utilização de um disjuntor com pistas de acrílico e colocação de aparelho fixo bimaxilar.

Descrição do caso clínico: Doente do género feminino, 12 anos, recorreu à consulta de Ortodontia do Instituto Universitário Egas Moniz com o motivo da consulta 'os dentes estão apinhados". Após análise clínica e radiográfica, diagnosticou-se uma mordida cruzada posterior com desvio mandibular para a direita, classe I esquelética e classe II molar e canina direita e classe I molar e canina esquerda. Após a obtenção do consentimento informado assinado o tratamento consistiu na utilização de um disjuntor com pistas oclusais de acrílico e aparatologia fixa bimaxilar.

Discussão e conclusões: Os disjuntores maxilares atuam diretamente na sutura palatina mediana, afastando-a meca- nicamente, corrigindo assim a dimensão transversal reduzida da arcada maxilar, com formação óssea. A utilização de um disjuntor com pistas de acrílico, permite a eliminação das interferências oclusais e o desbloqueio da mandíbula corrigindo o desvio mandibular e consequentemente a classe II dentária direita de forma espontânea. Neste caso clínico o recurso a um disjuntor com pistas de acrílico e a finalização e alinhamento dentário com recurso a aparelho fixo bimaxilar demonstrou ser uma técnica válida, com resultados satisfatórios e estabilidade a longo prazo sem recidivas no tratamento ortodôntico. http://doi.org/10.24873/j.rpemd.2018.11.303

\#067 Reconstrução do plano oclusal no tratamento das mordidas abertas

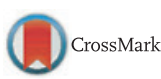

Gunel Kizi*, Rita Santos Almeida, Valter Alves, Ana Delgado

Instituto Universitário Ega Moniz

Introdução: O tratamento da mordida aberta anterior é um desafio para o ortodontista devido à sua complexidade e etiologia multifactorial (hábitos de sucção, obstrução das vias aéreas, respiração oral, onicofagia). Existem diversas formas de efetuar a sua abordagem terapêutica, nomeadamente a técnica Multiloop Edgewise Arch Wire (MEAW). Esta técnica foi introduzida por Kim em 1987, de forma a corrigir as más oclusões classe I, II, III e sobremordida profunda. Contudo, tem sido aplicada com elevada eficácia nos casos de mordida aberta anterior. O presente trabalho tem como objetivo a apresentação de um caso clínico de correção da mordida aberta anterior, recorrendo à técnica Multiloop Edgewise Arch Wire.

Descrição do caso clínico: Doente de género feminino, 20 anos de idade, compareceu na consulta Assistencial de Ortodontia da Clínica Universitária Egas Moniz, com a principal queixa: 'Tenho o palato pouco desenvolvido e os dentes da frente não tocam' SIC. Após a obtenção do consentimento informado devidamente assinado, na análise clínica observou-se: classe I molar e canina, constrição maxilar, apinhamento no $2 .^{\circ}$ e $5 .^{\circ}$ sextantes e perfil facial recto. Na análise radiográfica e cefalométrica: dentição definitiva, classe I esquelética e perfil mesofacial. O tratamento consistiu numa expansão maxilar com recurso a arcos australianos auxiliados por Mulligan, aparatologia fixa bimaxilar (Multiloop Edgewise Arch Wire) e aparelho de contenção superior e inferior.

Discussão e conclusões: A técnica Multiloop Edgewise Arch Wire, aplicada à mordida aberta anterior permite não só a eliminação da discrepância posterior, como também a reestruturação do plano oclusal e o reposicionamento mandibular, sem provocar alterações major no perfil facial do doente. O caso clínico apresentado demonstrou que é possível corrigir a mordida aberta anterior com recurso à técnica Multiloop Edgewise Arch Wire, obtendo-se uma oclusão estável e resultados estéticos e funcionais bastante satisfatórios. Deste modo, é possível concluir que a aplicação desta técnica é uma excelente abordagem terapêutica e uma excelente alternativa à intervenção cirúrgica. Durante os 8 meses de follow-up, foi mantida a estabilidade no tratamento de mordida aberta.

http://doi.org/10.24873/j.rpemd.2018.11.304 